\title{
Pancreatic Cancer Stem Cells: A State or an Entity?
}

Patrick C. Hermann ${ }^{1}$ and Bruno Sainz, Jr. 2,3,4*

${ }^{1}$ Department of Internal Medicine I, Ulm University, Germany.

${ }^{2}$ Department of Biochemistry, Universidad Autónoma de Madrid (UAM), Madrid, Spain.

${ }^{3}$ Department of Cancer Biology, Instituto de Investigaciones Biomédicas "Alberto Sols" (IIBM), CSIC-UAM, Madrid, Spain.

${ }^{4}$ Chronic Diseases and Cancer, Area 3 - Instituto Ramón y Cajal de Investigación Sanitaria (IRYCIS), Madrid, Spain.

*Corresponding author: Bruno Sainz, Jr., UAM, Calle del Arzobispo Morcillo 4, Madrid, Spain, 28029. Phone: +34 91-497-3385, Email: bruno.sainz@uam.es

DISCLOSURE OF POTENTIAL CONFLICT OF INTEREST: The authors declare no conflict of interest

Word count

Abstract: 286 words

Main Text (without references \& legends): 5535 words 


\begin{abstract}
Pancreatic ductal adenocarcinoma (PDAC), the most common type of pancreatic cancer, has a median overall survival of 6-12 months and a 5-year survival of less than $7 \%$. While PDAC currently represents the 4th most frequent cause of death due to cancer worldwide, it is expected to become the second leading cause of cancer-related death by 2030 . These alarming statistics are primarily due to the inherent chemoresistant and metastatic nature of this tumor, and the existence of a subpopulation of highly plastic "stem"-like cells within the tumor, known as cancer stem cells (CSCs). Since their discovery in 2007, we have come to realize that pancreatic CSCs have unique metabolic, autophagic, invasive, and chemoresistance properties that allow them to continuously self-renew and escape chemo-therapeutic elimination. More importantly, the concept of the CSC as a fixed entity within the tumor has also evolved, and current data suggest that CSCs are states rather than defined entities. Consequently, current treatments for the majority of PDAC patients are not effective, and do not significantly impact overall patient survival, as they do not adequately target the plastic CSC sub-population nor the transient/hybrid cells that can replenish the CSC pool. Thus, it is necessary that we improve our understanding of the characteristics and signals that maintain and drive the pancreatic CSC population in order to develop new therapies to target these cells. Herein, we will provide the latest updates and knowledge on the inherent characteristics of pancreatic CSCs and the CSC niche, specifically the cross-talk that exists between CSCs and niche resident cells. Lastly, we will address the question of whether a CSC is a state or an entity and discuss how the answer to this question can impact treatment approaches.
\end{abstract}




\section{Pancreatic Cancer}

When it comes to cancer, the past decade has seen great progress in the diagnosis and treatment of many tumor entities; however, the same cannot be said for pancreatic ductal adenocarcinoma (PDAC). Apart from being one of the most aggressive tumors, PDAC is currently the $4^{\text {th }}$ most frequent cause of cancer-related death, and due to its high aggressiveness, pronounced resistance to therapy and early metastatic spread, all of which are hallmarks of pancreatic cancer, PDAC is projected to become the second most lethal tumor by the year 2030 [1]. Less than $20 \%$ of PDAC patients present with localized (and thus potentially resectable and curative) disease at the time of diagnosis. In $15-20 \%$ of the patients, the tumor is already locally advanced (irresectable), and the remaining patients already present with metastatic pancreatic cancer [2-4]. Pancreatic cancer is more common in the elderly and occurs at similar frequency in females and males. The overall 5 -year survival rate is dismal at $<7 \%[5,6]$, and in spite of the use of different therapeutic strategies, the median survival is only 6-12 months [7-9].

Age, alcohol and chronic pancreatitis are typical but unspecific risk factors for pancreatic cancer development. Smoking has been associated with a 2.5 - 3.6\% increased risk of developing PDAC [10], and we have shown that nicotine exposure accelerates tumor formation in the context of KRAS mutations [11]. Indeed, certain genetic alterations and genetic syndromes have been closely associated with pancreatic cancer development. Most frequently, up to $90 \%$ of PDAC tumors harbor activating mutations in the KRAS oncogene $[12,13]$ and mutations or deletions in p16 (MTS1) [14] or Smad4 (DPC4) [15]. Almost as frequent are inactivating mutations in p53 [13], or the overexpression of receptor tyrosine kinases such as EGFR , FGFR, or IGF-1 [16-18]. These receptor kinases can, together with their ligands, influence not only tumor cell growth and invasion, but also metastatic activity (and thus survival) in PDAC. Interestingly, a sequence of genetic events comparable to the adenoma-carcinoma progression model proposed for colorectal cancer by Fearon and Vogelstein [19] seems to be applicable to pancreatic cancer: a sequence of increasingly dangerous precursor lesions (pancreatic intraepithelial neoplasia, PanIN) occurs with the accumulation of mutations such as KRAS, inactivation of CDKN2A and, finally of TP53 and SMAD4 [20]. Furthermore, the differentiation (or lack thereof) of cancer cells within pancreatic tumors has been strongly linked to the key properties of pancreatic cancer in the context of the cancer stem cell model of PDAC [21, 22], proposing that a specific subpopulation of undifferentiated cancer stem cells mediates not only tumorigenicity, but also therapy resistance and metastasis [21]. The CSC concept has been extensively reviewed and we refer the reader to the following recent publications [23] and [24]. In this review, however, we will tackle a less explored concept related to CSCs, which is the idea that CSCs are not hardwired defined entities but rather plastic states. 


\section{Cancer Stem Cells - hardwired defined entity or a plastic state}

Our understanding of cellular plasticity has been based largely on studies of adult stem cells, and a number of definitions have been proposed. In general, cellular plasticity can be defined as the ability of a cell to move up and down the differentiation lineage or hierarchy. Likewise, plasticity can also refer to a cell's phenotypic potential, that is, the potential of a cell to adopt a new identity or fate in response to different conditions or environmental cues. While fundamentally believed to be a trait exclusive of stem cells, we now appreciate that daughter cells, progenitor cells, transient cells and even "committed" differentiated cells are plastic and can undergo phenotypic transitions and/or move throughout the hierarchal continuum. Thus, non-stem cells can reenter the linear and hierarchical process of cellular differentiation when necessary, challenging the idea of a fixed unidirectional hierarchal structure with the stem at the top. Using the liver as an example, it has been shown that terminally differentiated hepatocytes are plastic and upon liver damage can give rise to hepatocytes without actually becoming full-fledged stem cells [25]. Similar plasticity in non-stem cells has been observed in the mouse intestine. Numerous studies have shown that "committed" differentiated cells of the secretory or enterocyte lineage can replace Lgr5+ intestinal stem cells upon their elimination. Thus, daughter cells and even fully differentiated cells can reenter the niche to replace stem cells when lost, a process known as neutral competition, where stem cell progenies (daughter cells) respond to extrinsic signaling factors and compete to occupy the niche [23, 26-28]. With respect to the exocrine pancreas, it is uncertain whether neutral competition occurs as a defined stem cell compartment has not been conclusively identified; however, acinar cells alone are extremely plastic and can change their lineage fate by undergoing epithelial-to-epithelial transition or EMT and transdifferentiate into ductal or endocrine cells and even adipocytes in response to appropriate stimuli $[29,30]$. Therefore, the existence of cells, including "committed" differentiated cells, with differing degrees of plasticity may be more common than previously believed.

In the context of cancer, plasticity has been largely and exclusively associated only to CSCS [31] as it was generally accepted that limited plasticity existed across non-CSCs. In fact, prior to 2017, it was widely accepted that there existed a fixed unidirectional hierarchal structure within solid tumors, and at the apex of this hierarchy was a defined subpopulation of rare "hardwired" stem-like cells with unlimited self-renewal capacity and multi/pluripotent potential. By definition, these cells are the sole source of tumor initiation, metastasis and cellular heterogeneity, giving rise to intermediate progenitors and terminally-differentiated bulk tumor 
cells. Likewise, only these cells can undergo phenotypic transitions to adapt to stimuli, microenvironmental cues or chemotherapeutic challenge. Evidence to support this unidirectional hierarchal model first came from intratumor heterogeneity studies performed in the late 1950s and early 1960s showing that not all cells from murine cancers had the ability to form de novo tumors following transplantation into syngeneic hosts. With the advent of fluorescence-activated cell sorting techniques and the availability of immunocompromised mice, Lapidot et al. [32] formally showed in 1994 that Acute Myeloid Leukemia (AML) is composed of multiple cell types, with CD34+/CD38- cells representing the cells with exclusive tumorigenic potential. Since then, and for the past 20 years, hundreds of papers have been published providing evidence to support the CSC model across different tumor types and entities using both mouse and human systems. It is important to highlight that the majority of these studies have relied on extreme limiting dilution CSC-transplantation assays as evidence for the existence of CSCs in cultured cells, resected tumors or patient-derived xenografts [21, 22, 3241]. This approach consists in isolating tumor cells based on the expression of cell surface markers or other functional properties and injecting them into immunocompromised mice to determine tumor efficiency as a function of the number of cells injected. While such transplantation approaches have supported the existence of CSCs, these assays are not without their limitations. For example, the simple transplantation of human cells into immunocompromised mice is a selection process, and it is to be expected that human tumor cells of different tumor types and from different locations within the same tumor can adapt differently to "growth in a foreign (mouse) milieu", as stated and shown by Kelly et al. as early as 2007 [42]. In addition, the expression of cell surface markers can vary depending on the source from which the CSCs are isolated (primary tumor versus patient-derived xenograft (PDX) versus primary cell culture) or the tissue digestion or cell suspension protocols used. Likewise, the expression of most markers is neither exclusively nor reproducibly linked to a functional CSC phenotype across or even within similar tumor types [39]. Indeed, the number of surface markers used and the use of different markers and isolation methodologies has created conflicting data in some settings [43], emphasizing the limitations associated with isolating pure CSC populations from different settings.

Fortunately, genetic-based approaches, such as lineage tracing experiments, have complemented extreme limiting dilution CSC-transplantation assays to support the concept that CSCs are exclusively responsible for tumor formation and tumor heterogeneity. For example, Driessens et al. performed clonal analysis of squamous skin tumors using genetic lineage tracing to show that injected cells were not homogenous, but rather consisted of a large fraction of cells with limited long-term proliferative potential and a smaller fraction of cells with persistent long- 
term proliferation and tumor forming capacity [44]. In an elegant study published by Schepers et al. in 2012, the multicolor Cre-reporter R26R-Confetti was used to lineage trace leucine-rich repeat-containing heterotrimeric guanine nucleotide-binding protein-coupled receptor 5 positive ( $\operatorname{Lgr} 5+)$ cells in a mouse model with conditional deletion of the tumor-suppressor gene $A p c$. Using this system, the authors demonstrated that the rare Lgr5+ cells (representing about 5 to $10 \%$ of the cells in the adenomas) are the drivers of primary intestinal adenomas and have the capacity to give rise to other Lgr5+ cells as well as to all of the other cells present with the adenomas [45]. In a PDAC mouse model, Maddipati and Stanger used multi-color lineage tracing technology to follow the cellular dynamics of metastasis in vivo [46]. While the goal of their study was not to track pancreatic CSCs, they examined the heterogeneity of primary tumors from the first initial stages of tumor development to metastasis development. Interestingly, the authors showed that not all cells could successfully extravasate and proliferate at secondary sites. Colonization of secondary organs was limited to a small subset of cells, and while metastatic lesions would begin as polyclonal, they would rapidly lose their polyclonality and become dominated by a single clonal population. The conclusion of this study supports the concept of a CSC-like cell also driving metastatic tumor formation in secondary organs in PDAC.

Similar lineage tracing experiments in human cancers have not been as common due to the complex genetic modifications required for such experiments. Nonetheless, with the use of lentiviral infection systems to tag human cells, a number of studies have been able to analyze and track stem cell hierarchies in human cancers. For example, Dieter et al. used a linear amplification-mediated PCR-based approach for molecular tracking of sphere-derived colon cancer tumor initiating cells (TICS) in vivo [47]. Using this strategy, the authors identified three types of TICs following serial transplantation of cells from primary to tertiary mice: extensively self-renewing long-term TICS (LT-TICS), tumor transient amplifying cells (T-TACS) and rare delayed contributing TICS (DC-TICS). Of these three TICs, LT-TICs possessed long-term selfrenewing capacity and were responsible for metastasis formation, and DC-TICs represented a silent subpopulation of cells that did not contribute quantitatively to tumor formation in primary transplanted mice but could be recruited to the tumor and were active during secondary and tertiary transplantation. T-TACs, on the other hand, had limited self-renewal capacity and did not contribute to long-term tumor formation. Thus, similar to the mouse lineage tracing experiments detailed above, tumor formation in human colon cancer was shown to be mediated by a subpopulation of distinct cells with self-renewing capacity. A recent study by Cortina et al. utilized CRISPR/Cas9 technology to integrate a lineage-tracing cassette in the LGR5 locus in human CRC organoids [48]. Using this approach, the authors also show that LGR5+ CRC cells self- 
renew and generate progeny over long periods of time, and CRC adopts a hierarchical organization reminiscent of normal colonic epithelium.

Taken together, the aforementioned studies provided direct functional evidence for the existence of CSCs within primary tumors and have played an important role in defining CSCs as rare, typically quiescent self-renewing cells within the tumor bulk that are hardwired and possess stem-like characteristics that bestow upon them exclusive tumorigenic properties, intrinsic cellular plasticity and the capacity to hierarchically organize the tumor. Likewise, nonCSCs, which make up the bulk of the tumor, possess only transient proliferative capacity, are not plastic and consequently do not participate in long-term tumor maintenance; however, some cells can be active during serial transplantation or during processes such as metastasis. While these studies are convincing and have shaped the definition of the CSC over the past two decades, more recent studies have challenged this strict hierarchical structure. For example, the authors that showed the existence of three types of TICs in human colon cancer cells recently applied the same strategy to PDAC and demonstrated that T-TACS also exist in PDAC, and unlike what was observed in colon cancer cells, PDAC T-TACs can drive long-term progression in serial transplantation assays in vivo via temporally restricted bursts, which they associated to an unexpected functional and phenotypic plasticity of pancreatic TICs in vivo [49]. The authors go one step further to propose that CSCs (or TICs) are not fixed hardwired entities, but rather states and therefore from a therapeutic perspective, therapies for PDAC should be designed "to target TIC activation, rather than a fixed TIC population."

The concept that CSCS are neither the sole drivers of long term tumor formation/maintenance or a defined hardwired fixed entity in primary tumors is a revolutionary concept, but one that has been proposed on many occasions [50,51]. A number of studies have provided strong evidence that challenges the classical view of a hardwired CSC state. As early as 2007, Zheng et al. [52] showed that all of the cells present in the C6 glioma cell line, regardless of the expression of $\mathrm{CD} 133$ or their side population status, could generate clones when plated as single cells in miniwells, and all clones had tumorigenic capacity when transplanted in BALB/Cnude mice. This study concluded that so-called non-CSCs (i.e. CD133-) were indeed CSCs. In 2011, Gupta et al. showed that stochastic state transitions give rise to phenotypic equilibrium in the breast cancer cell lines SUM149 and SUM159 [53]. In their study the authors showed that sorted breast cancer stem-like cells, purified based on a basal- or luminal-like phenotype state, returned towards equilibrium proportions over time via a stochastic process, leading the authors to predict that breast cancer stem-like cells arise de novo from non-stem-like cells, and experimentally raising for the first time the idea that "simply targeting a cancer stem cell population will not necessarily prevent tumor recurrence" [54]. While revolutionary at their 
times, additional studies since then now further support the concept that CSCs are a state rather than an entity, and CSCs can be replenished by plastic non-CSCs via specific environmental cues. Specifically, two recent and separate studies published in 2017 targeting the $\operatorname{Lgr5}^{+}$CSC population in colon cancer organoid cultures have provided strong evidence to support the notion that CSCs are not a hardwired state, and direct targeting of a defined CSC population does not result in tumor eradication as plastic non-CSCs can facilitate their replenishment. In the first study, de Sousa e Melo et al. used mouse-derived $\mathrm{Apc}^{\mathrm{min}} ; \mathrm{Kras}^{\mathrm{G12V}} ; \mathrm{p} 53^{\mathrm{CRIPSR}} ; \mathrm{SMAD4} 4^{\mathrm{CRIPSR}}$ organoid cultures engineered to express EGFP and the diphtheria-toxin (DT) receptor under the control of the LGR5 ${ }^{+}$promoter to initiate tumor growth in recipient mice [55]. The authors hypothesized that if LGR5+ CSCs are the sole mediators of tumor growth; their elimination should ablate tumor progression. Indeed, upon treatment with DT, organoid-derived tumor growth was halted and LGR5+ cells were eliminated as indicated by a loss of EGFP+ cells. In a second study, Shimokawa et al. eliminated the $\mathrm{Lgr}^{+} \mathrm{CSC}$ population in human colorectal cancer organoid cultures by inserting an inducible version of the suicide-gene caspase 9 (iCasp9) into the LGR5 locus [56]. Similar to what Melo et al. observed, the growth of the organoid-derived xenografts was significantly reduced in vivo upon iCasp9 induction. In both studies, however, upon removal of DT or the inducer, the LGR5 ${ }^{+}$population re-emerged and tumors regrew, which the authors concluded was due to cellular plasticity driven by a non-CSC (or LGR5-negative) transient population. In the study by Shimokawa et al., the authors observed that KRT20 expressing differentiated tumor cells were the cells that restored the LRG5+ CSC population. Interestingly, in a mouse model of glioma, Chen et al. used a nestin- $\triangle$ TK-IRES-GFP transgene to label a subset of endogenous glioma tumor cells and showed that combined temozolomide and ganciclovir treatment (which specifically eliminated TK expressing cells) impeded tumor development [57]; however, while in their model, ablation of the CSC-like cells efficiently abrogated tumor growth, no apparent replenishment of the CSC pool from other glioblastoma cells was observed. Therefore, the concept that non-CSCs can replenish the CSC pool, and thus targeting the CSC population will not result in tumor eradication, may be tumor-type specific. Altogether, however, these studies highlight that CSC-ness is not an intrinsic feature of a subpopulation of cells, but rather, CSC-ness is a state governed and driven by temporal and spatial characteristics [51]. While future studies similar to those described above will be necessary to definitively show that pancreatic CSCs are also a state rather than an entity, data to date do not suggest the contrary. In Figure 1 we summarize the major concepts discussed in this section, including tumor hierarchy, CSC cell division, and plasticty.

\section{How the microenvironment regulates CSC-ness and plasticity}


Without a doubt, the tumor microenvironment (TME), a collective term for the nonneoplastic stroma cells and tumor milieu [58], can temporally and spatially influence tumor cells and CSCs via a complex cross-talk in the form of secreted factors and cell-to-cell contacts. This cross-talk is complex and dynamic and can encompass communication between, but not limited to, the CSCs and other non-CSCs, CSCs and tumor stromal cell, and non-CSCs and tumor stromal cells.

When discussing the CSC in the context of the TME, it is important to focus on the CSC niche. Like normal stem cells, CSCs are believed to reside in a niche within the TME. The niche is essentially a specialized compartment that regulates stem cell (or CSC) fate through cell-to-cell contacts or via cues from the secreted milieu. One can think of the CSC niche as a smaller anatomically distinct and more specialized TME sub compartment, as the CSC niche contains basically the same cellular and non-cellular components that are present in TME [59]. It is important to emphasize that the tumor microenvironment and CSC niche of each tumor type is different, and important differences in the make-up of the stroma at the cellular and noncellular levels exists even in tumors of the same type or same sub-type. Thus, we are still far from completely understanding the TME, and more so the CSC niche.

The PDAC microenvironment (Figure 2) has been extensively studied and reviewed in [60] and [61]. It is unique in and of itself, largely due to its high desmoplastic reaction, resulting in an abundant and dense collagenous and hypoxic stroma $[62,63]$. At the cellular level, the PDAC microenvironment is composed of pancreatic stellate cells (PaSC) [64-67] (which are often referred to as cancer-associated fibroblasts), immune cells (lymphocytes, tumor-associated macrophages (TAMs), myeloid-derived suppressor cells, macrophages, mast cells, and dendritic cells) [68-70], endothelial cells, neuronal cells/nerve fibers [68] and bone marrow-derived stem cells [71]. While individually all of these cellular components have their specific functions, in the context of the TME, these cells create the dynamic and complex TME. Herein we will focus our discussion on PaSCs and TAMs.

PaSCs are naturally quiescent resident cells of the exocrine pancreas that can be activated by growth factors (platelet-derived growth factor and TGF- $\beta 1$ ), pancreatitis, tumor formation or injury. In the context of PDAC, activated PaSCs form the bulk of the tumor fibrotic microenvironment, and upon activation these cells can proliferate, secrete extracellular matrix (ECM) proteins (such as fibronectin, proteoglycans, hyaluronic acid, growth factors, proteinases and collagen type I), and up-regulate intracellular activation markers such as $\alpha$-smooth muscle actin ( $\alpha$-SMA) [72]. Their role in forming the extremely fibrotic PDAC stroma also contributes to the poor vascularization and subsequent hypoxic microenvironment characteristic of PDAC 
tumors [63, 72]. In addition to acting as a physical component of the tumor, PaSCs have been shown to support tumor growth, cancer cell migration, prevent tumor cell apoptosis, and promote chemoresistance [73-76], often through the secretion of factors such as Periostin, Tenascin-C and Wnt2 [77-80] as well as chemokines and cytokines, such as IL-6 [81]. Recently Orozco et al identified galectin-1 (Gal1), a soluble factor secreted by PaSC, as a key regulator of the crosstalk between tumor non-CSCs and tumor stromal cells, which can promote PDAC cell proliferation, tumor development and metastasis, tumor angiogenesis and modulation of inflammatory responses [82]. Importantly, the authors demonstrate that depletion of Gal1 in PaSCs co-injected orthotopically with the BxPC-3 pancreatic cell line reduced tumor size, angiogenesis, stroma activation and metastasis, and genetically depleting Gal1 in the Ela$\mathrm{Kras}^{G 12 \mathrm{~V}}$; $\mathrm{p53}{ }^{-/-}$PDAC mouse model facilitated immune cell infiltration in vivo. Thus, this exciting study highlights the therapeutic value of targeting this protein with Gal1-specific inhibitors for the treatment of PDAC.

In 2011 and 2012, Lonardo et al. and Hamada et al., respectively, showed that apart from their role in promoting the PDAC desmoplastic fibrotic environment, PaSCs form a niche for pancreatic CSCs and via secreted factors promote their self-renewal, tumorigenic and invasive capacities [67] [74]. For example, Lonardo and colleagues showed that PaSCs promoted CSC properties through secretion of the embryonic morphogens Nodal/Activin, which bind to the Activin-like 4 (Alk4) receptor presents on pancreatic CSCs. The authors further hypothesized that in the context of the tumor, the pancreatic CSC phenotype is maintained by paracrine Nodal/Activin signaling within the CSC niche [67]. Nodal and Activin, TGF superfamily protein members, bind to their receptors to exert multiple, and sometimes opposing, effects on a variety of cell types. In PDAC, TGF superfamily proteins have been long known to play important roles in PDAC cell growth and metastasis [83], but in 2011, Heeschen and colleagues showed that while Nodal and Activin were hardly detectable in more differentiated pancreatic cancer cells, CSCs markedly overexpressed both proteins and their receptor Alk4/7. Importantly, knockdown or pharmacological inhibition of Alk4/7 significantly abrogated CSC self-renewal, in vivo tumorigenicity and reversed the resistance of orthotopically transplanted CSCs to gemcitabine [84], demonstrating that this pathway is vital for maintaining the stem-like state of CSCs. Subsequent publications by Cioffi et al. [85] and Zagorac et al. [86] would add to this story by showing that the miR17-92 cluster of miRNAs is epigenetically repressed in pancreatic CSCs as many of the targets of this cluster are involved in Nodal/Activin signaling, such as Alk4. In a separate study, Al-Assar et al. showed that PaSC can also secrete TGF $\beta 1$, and TGF $\beta$-neutralizing antibodies could inhibit CSC processes, such as resistance to radiotherapy and in vivo tumorigenicity. Thus, the ability to PaSCs to maintain the CSC phenotype via paracrine TGF 
superfamily protein signaling represents an important discovery and potential therapeutic target. At the level of plasticity, it is likely that the factors secreted by PaSCs (e.g. TGF $\beta 1$ ) not only modulate the CSC and its inherent state and plasticity, but also the plasticity of non-CSCs, such as transit-amplifying, hybrid, progenitor, and even differentiated tumor cells. While no studies to date have explored this concept in depth in PDAC, studies in other tumor entities, such as hepatocellular carcinoma, prostate cancer and breast cancer, have shown that factors secreted by cancer-associated fibroblasts can affect tumor and non-tumor cell plasticity [87-91]. For example, a study by Geary et al. reported that CAF-secreted annexin A1 induces prostate cancer cells to gain stem cell-like features [87]. Time will tell if similar reprogramming of the non-CSC compartment via PaSC-secreted factors occurs in PDAC.

Infiltrating immune cells in the PDAC tumor microenvironment also play important and dynamic roles. For example, it has long been known that the desmoplastic microenvironment in pancreatic cancer promotes leukocyte cell recruitment, which in turn promotes matrix remodelling [92, 93]. Of the many immune cell infiltrates present in the PDAC microenvironment, TAMs, also known as M2, "alternatively-activated", or "pro-tumorigenic" macrophages, are the major cell type of the inflammatory infiltrates present in PDAC tumors $[94,95]$. Macrophages are classically activated towards the M1 phenotype, characterized by high expression of the pro-inflammatory cytokines IL-1, IL-6, IL-12, and tumor necrosis factor; however, in response to alternate environmental stimuli, such as the TME and/or IL-4, IL-13, and IL-10, macrophages can be activated towards an " $\mathrm{M} 2$ " phenotype promoting tumorigenesis, matrix remodelling, and metastasis $[92,93,96]$. Importantly, TAMs can also activate CSCs and promote their plasticity. This concept has been recently reviewed in [97], and we discuss in the following section how TAMs can modulate the plasticity of PDAC CSCs and non-CSC and how this crosstalk can be therapeutically targeted.

Lastly, the non-cellular components of the TME, such as extracellular matrix (ECM) proteins, can also influence the plasticity of cancer cells. The PDAC fibrotic desmoplastic reaction is composed of a collagen type I-rich ECM, and studies have shown that the amount of collagen present can determine tumor aggressiveness [98-100]; however, how ECM composition regulates tumor aggressiveness or CSC dynamics and invasive growth has yet to been fully characterized. However, in a recent study by Biondani et al., the authors generated a series of 3D organotypic culture platforms composed of Matrigel matrices, a basement membrane made up of laminin-rich extract (which they claimed to "represent a stromal microenvironment at the initial phases of tumor development") and increasing concentrations of collagen type I [101]. Using this system, they observed that they could modulate the plasticity of Panc-1-derived CSCs towards a mesenchymal or epithelial phenotype based on the ECM component used. For 
example, when grown on Matrigel-enriched organotypic culture, the CSCs adopted a more mesenchymal phenotype, while organotypic cultures rich in collagen type I favoured an epithelial phenotype. In contrast, Matrigel promoted non-CSCs to grow as spheroid-like colonies, which could be reprogrammed into a more epithelial monolayer-like culture as the collagen type I content increased. Together this study shows how the ECM can differentially influence CSC and non-CSC plasticity. Importantly, collagen type $V$ is also present in the ECM of PDAC tumors. Collagen type $V$ is a fibrillar, regulatory collagen that is up-regulated in the TME and expressed by PaSCs. Similar to collagen type I, collagen type $\mathrm{V}$ over expression correlated with a malignant phenotype and promoted adhesion, migration and viability of various pancreatic cancer cell lines [102]. While the authors did not evaluate whether collagen type V over expression induced stem-like characteristics in the non-CSC population or activated the CSC compartment, it is likely that other ECM proteins can also modulate the plasticity of non-CSCs and CSCs, similar to that of collagen type I.

\section{Targeting CSC plasticity - therapeutic options}

The identification and investigation of CSCs is not an end in itself. Since the undeniable role of these cells in tumorigenesis, therapy resistance and metastasis has been shown, these cells need to be eliminated in order for a therapy to be curative, even more so since even a single CSC is theoretically able to reconstitute the entire tumor. Possible strategies for their elimination have been recently reviewed [103], and include i) a direct targeted elimination of CSCs (known as targeted therapy), ii) promoting an active cell cycle to make quiescent CSCs accessible for therapy or iii) a disruption of the CSC niche and/or TME. Below we highlight some key and important studies.

In our laboratories, we have shown several times that treatment with chemotherapies such as gemcitabine only results in a relative enrichment in $\operatorname{CSCs}[21,104-106]$; however, the combination of chemotherapy with CSC inhibitors achieved more curative and promising results. For example, the sonic hedgehog $(\mathrm{SHH})$ pathway and the mTOR (mammalian target of rapamycin) pathways are highly activated in pancreatic CSCs $[104,106]$. While the inhibition of each pathway individually did not eliminate CSCs, the combined inhibition of both pathways together with standard chemotherapy not only eradicated pancreatic CSCs, but also significantly reduced tumor burden and resulted in the long-time survival of treated mice bearing xenografts of primary pancreatic cancer patient tissue $[104,106]$. Interestingly, the inhibition of SHH also resulted in significant depletion of the stroma, presumably removing the desmoplastic barrier that impedes treatment delivery [107]. However, a phase II study using Saridegib (IPI-926), an upstream inhibitor of the SHH pathway, in combination with gemcitabine actually showed worse 
results for the combination group as compared to the gemcitabine mono group, which led to the discontinuation of this study, as well as other studies evaluating stronger chemotherapeutic regimen such as FOLFIRINOX [108]. Since K-RAS actually induces the downstream SHH effector proteins GLI-1 and GLI-2 [109], it would be very interesting to see the effects of GLI inhibitors in combination with chemotherapy.

Others have tested the effects of targeting other stem cell-related pathways such as Wnt (reviewed in [110]), Stat3 or Notch (reviewed in [111, 112]). In the case of Notch inhibition, an array of gamma secretase inhibitors, Notch receptor or Notch ligand inhibitors are currently being tested in clinical trials. For example, Demcizumab, a humanized monoclonal antibody against the Notch ligand delta-like 4 (DLL4), is currently being tested in the YOSEMITE trial, comparing treatment effects of Demcizumab + gemcitabine + nab-paclitaxel (Abraxane, ABX) versus gemcitabine + nab-paclitaxel alone. Disappointingly, the study shows no benefit of Demcizumab co-treatment as compared to gemcitabine + ABX alone. In contrast, the Stat3inhibitor Napabucasin (BBI-608) has shown promising results in two phase Ib/II studies: the combination of Napabucasin + FOLFIRI + ABX (CanStem111P) is being investigated in pancreatic cancer, and the combination of Napabucasin + FOLFIRI +/- Bevacizumab is being investigated in colorectal cancer. Interestingly, both studies' interim analyses show promising anti-tumor effects.

A recently discovered feature of pancreatic CSCs is their extensive dependency on mitochondrial oxidative phosphorylation (OXPHOS) [113], controlled by the transcription factor PGC-1 $\alpha$, and negatively regulated by the expression of c-MYC. Importantly, this dependence of CSCS on OXPHOS to meet their energy requirements is by no means specific for pancreatic cancer, as a similar dependence has been observed in various other tumor entities, such as brain and lung cancer as well as leukemia. The high dependency on OXPHOS and the subsequently high energy yield is thought to be due to the nutrient-deprived microenvironment of cancer (stem) cells, and due to this strong dependency on OXPHOS, CSCs are more susceptible to drugs interfering with mitochondrial respiration, e.g. metformin. Indeed, we have shown previously that metformin exerts multiple effects on the CSC population. For example, through metabolic reprogramming CSC numbers are significantly reduced in vitro as well as in vivo $[113,114]$. Additionally, we demonstrated recently that metformin inhibits nicotine-induced dedifferentiation of pancreatic tissue and prevents PanIN progression in a mouse model of pancreatic cancer [11].

Like other stem cells, and as discussed above, CSCs reside in a tightly controlled niche providing nutrients, oxygen, and protection from outside influences. Thus, therapeutic disruption of the CSC niche represents another potential way to eliminate CSCs. We have 
recently focused our attention on targeting TAMs, one of the major key cellular components of the TME that function to maintain CSCs and to support their activation. TAMs secrete numerous pro-tumor and pro-CSC factors (reviewed in [97]). Specific to PDAC, we showed that TAMs secrete the immune modulatory peptide LL-37 (leucine leucine-37, also known as human cationic antimicrobial peptide 18 or hCAP-18) in direct correlation with the aggressiveness of the tumor. While no relevant amount of LL-37 is detectable in normal pancreatic tissue, secretion is highest in advanced tumors or metastases. LL-37 promotes the expression of stemness-associated genes, sphere formation and most importantly tumor formation in vivo. The secretion of LL-37 is stimulated by Nodal/Activin and TGFß-1 secreted by CSCs, which in turn carry the LL-37 receptors P2X7R and FPR2. This signaling cross-talk leads to a positive feedback loop between TAMs and CSCs, further propagating cancer stem cell features by signaling from the niche. Inhibition of the receptors, however, can successfully disrupt this feedback loop and significantly reduces CSC numbers and functional activity [115]. Likewise, TAMs also secrete interferon stimulated gene 15 (ISG15), and we have shown that ISG15 can act directly on the CSC pool to enhance their self-renewal, pluripotency, tumorigeneses and migratory/invasive capacities [116]. While no inhibitors to date exist to block secreted ISG15, its receptor, the LFA1 (CD11a/CD18; aLb2 integrin) receptor, was recently discovered [117], and in theory therapies with monoclonal antibodies to neutralize TAM-secreted ISG15 or block the LFA-1 receptor could be developed to disrupt the CSC niche.

\section{Concluding remarks}

In this review we attempt to shed light on the ever-growing concept that the CSC is not a hardwired entity but rather a state. With the recent publications by de Sousa e Melo et al. and Shimokawa et al., this concept is even more evident and at the same time worrisome, as both studies showed that non-CSCs can replenish the CSC pool $[55,56]$. While this notion is not new [50-54], it highlights that the targeted therapies detailed above might be ineffective if used alone and not in combination with therapies that also target the CSC niche and non-CSCs. Likewise, it cannot be ruled out that the non-CSC population(s) that replenish the CSC pool in the aforementioned studies may very well be CSCs that have temporarily transitioned to a nonCSC or more differentiated state via cell-autonomous epigenetic mechanisms or via non-cellautonomous modifications mediated by cues received from the CSC niche and/or larger TME (Figure 3). Thus, care must be taken when 1) defining the non-CSC population that replenishes the CSC pool and 2) designing new therapies to target this yet undefined population. With this in mind, the question that remains unanswered is, do the transit-amplifying, hybrid, progenitor, or differentiated tumor cells revert to a dedifferentiated CSC state when the CSCs are lost or 
eliminated [118], or is the CSC pool replenished by a CSC population that is constantly entering and exiting the CSC state - fluctuating between a CSC and non-CSC state, but all along retaining their intrinsic underlying CSC "wiring"? Undoubtedly more research in this field is still required before we can address this unknown.

\section{Acknowledgments}

Work in the laboratory of PCH is supported by a Max Eder Fellowship of the German Cancer Aid (111746), and by a Hector Foundation Cancer Research grant. Work in the laboratory of BS is supported by a Rámon y Cajal Merit Award from the Ministerio de Economía y Competitividad, Spain, a Clinic and Laboratory Integration Program (CLIP) grant from the Cancer Research Institute (CRI), NY, a Coordinated grant from the Fundación Asociación Española Contra el Cáncer (AECC), and a Fondo de Investigaciones Sanitarias (FIS) grant PI15/01507 from the ISCIII.

\section{References}

[1] L. Rahib, B.D. Smith, R. Aizenberg, A.B. Rosenzweig, J.M. Fleshman, L.M. Matrisian, Projecting cancer incidence and deaths to 2030: the unexpected burden of thyroid, liver, and pancreas cancers in the United States, Cancer Res 74(11) (2014) 2913-21.

[2] R.E. Brand, M.A. Tempero, Pancreatic cancer, Curr Opin Oncol 10(4) (1998) 362-6.

[3] H.A. Burris, 3rd, M.J. Moore, J. Andersen, M.R. Green, M.L. Rothenberg, M.R. Modiano, M.C. Cripps, R.K. Portenoy, A.M. Storniolo, P. Tarassoff, R. Nelson, F.A. Dorr, C.D. Stephens, D.D. Von Hoff, Improvements in survival and clinical benefit with gemcitabine as first-line therapy for patients with advanced pancreas cancer: a randomized trial, J Clin Oncol 15(6) (1997) 2403-13. [4] H.J. Wanebo, M.P. Vezeridis, Pancreatic carcinoma in perspective. A continuing challenge, Cancer 78(3 Suppl) (1996) 580-91.

[5] J. Kleeff, M. Korc, M. Apte, C. La Vecchia, C.D. Johnson, A.V. Biankin, R.E. Neale, M. Tempero, D.A. Tuveson, R.H. Hruban, J.P. Neoptolemos, Pancreatic cancer, Nat Rev Dis Primers 2 (2016) 16022.

[6] A. Jemal, R. Siegel, J. Xu, E. Ward, Cancer statistics, 2010, CA Cancer J Clin 60(5) (2010) 277300.

[7] A.L. Warshaw, C. Fernandez-del Castillo, Pancreatic carcinoma, N Engl J Med 326(7) (1992) 455-65.

[8] S. Rosewicz, B. Wiedenmann, Pancreatic carcinoma, Lancet 349(9050) (1997) 485-9.

[9] M. Hedberg, A. Borgstrom, S. Genell, L. Janzon, Survival following pancreatic carcinoma: a follow-up study of all cases recorded in Malmo, Sweden, 1977-1991, Br J Surg 85(12) (1998) 1641-4.

[10] M.M. Hassan, M.L. Bondy, R.A. Wolff, J.L. Abbruzzese, J.N. Vauthey, P.W. Pisters, D.B. Evans, R. Khan, T.H. Chou, R. Lenzi, L. Jiao, D. Li, Risk factors for pancreatic cancer: case-control study, Am J Gastroenterol 102(12) (2007) 2696-707.

[11] P.C. Hermann, P. Sancho, M. Canamero, P. Martinelli, F. Madriles, P. Michl, T. Gress, R. de Pascual, L. Gandia, C. Guerra, M. Barbacid, M. Wagner, C.R. Vieira, A. Aicher, F.X. Real, B. Sainz, Jr., C. Heeschen, Nicotine Promotes Initiation and Progression of KRAS-Induced Pancreatic Cancer via Gata6-Dependent Dedifferentiation of Acinar Cells in Mice, Gastroenterology 147(5) (2014) 1119-33. 
[12] C. Almoguera, D. Shibata, K. Forrester, J. Martin, N. Arnheim, M. Perucho, Most human carcinomas of the exocrine pancreas contain mutant c-K-ras genes, Cell 53(4) (1988) 549-54.

[13] N.S. Pellegata, F. Sessa, B. Renault, M. Bonato, B.E. Leone, E. Solcia, G.N. Ranzani, K-ras and p53 gene mutations in pancreatic cancer: ductal and nonductal tumors progress through different genetic lesions, Cancer Res 54(6) (1994) 1556-60.

[14] C. Caldas, S.A. Hahn, L.T. da Costa, M.S. Redston, M. Schutte, A.B. Seymour, C.L. Weinstein, R.H. Hruban, C.J. Yeo, S.E. Kern, Frequent somatic mutations and homozygous deletions of the p16 (MTS1) gene in pancreatic adenocarcinoma, Nat Genet 8(1) (1994) 27-32.

[15] A.M. Grau, L. Zhang, W. Wang, S. Ruan, D.B. Evans, J.L. Abbruzzese, W. Zhang, P.J. Chiao, Induction of p21waf1 expression and growth inhibition by transforming growth factor beta involve the tumor suppressor gene DPC4 in human pancreatic adenocarcinoma cells, Cancer Res 57(18) (1997) 3929-34.

[16] M. Korc, B. Chandrasekar, Y. Yamanaka, H. Friess, M. Buchier, H.G. Beger, Overexpression of the epidermal growth factor receptor in human pancreatic cancer is associated with concomitant increases in the levels of epidermal growth factor and transforming growth factor alpha, J Clin Invest 90(4) (1992) 1352-60.

[17] U. Bergmann, H. Funatomi, M. Yokoyama, H.G. Beger, M. Korc, Insulin-like growth factor I overexpression in human pancreatic cancer: evidence for autocrine and paracrine roles, Cancer Res 55(10) (1995) 2007-11.

[18] M. Wagner, M.E. Lopez, M. Cahn, M. Korc, Suppression of fibroblast growth factor receptor signaling inhibits pancreatic cancer growth in vitro and in vivo, Gastroenterology 114(4) (1998) 798-807.

[19] E.R. Fearon, B. Vogelstein, A genetic model for colorectal tumorigenesis, Cell 61(5) (1990) 759-67.

[20] G. Feldmann, R. Beaty, R.H. Hruban, A. Maitra, Molecular genetics of pancreatic intraepithelial neoplasia, J Hepatobiliary Pancreat Surg 14(3) (2007) 224-32.

[21] P.C. Hermann, S.L. Huber, T. Herrler, A. Aicher, J.W. Ellwart, M. Guba, C.J. Bruns, C. Heeschen, Distinct populations of cancer stem cells determine tumor growth and metastatic activity in human pancreatic cancer, Cell Stem Cell 1(3) (2007) 313-23.

[22] C. Li, D.G. Heidt, P. Dalerba, C.F. Burant, L. Zhang, V. Adsay, M. Wicha, M.F. Clarke, D.M. Simeone, Identification of pancreatic cancer stem cells, Cancer Res 67(3) (2007) 1030-7.

[23] E. Batlle, H. Clevers, Cancer stem cells revisited, Nat Med 23(10) (2017) 1124-1134.

[24] S. Valle, L. Martin-Hijano, S. Alcala, M. Alonso-Nocelo, B. Sainz, Jr., The Ever-Evolving Concept of the Cancer Stem Cell in Pancreatic Cancer, Cancers (Basel) 10(2) (2018).

[25] B.Z. Stanger, Cellular homeostasis and repair in the mammalian liver, Annu Rev Physiol 77 (2015) 179-200.

[26] D.P. Doupe, A.M. Klein, B.D. Simons, P.H. Jones, The ordered architecture of murine ear epidermis is maintained by progenitor cells with random fate, Dev Cell 18(2) (2010) 317-23.

[27] H.J. Snippert, L.G. van der Flier, T. Sato, J.H. van Es, M. van den Born, C. Kroon-Veenboer, N. Barker, A.M. Klein, J. van Rheenen, B.D. Simons, H. Clevers, Intestinal crypt homeostasis results from neutral competition between symmetrically dividing Lgr5 stem cells, Cell 143(1) (2010) 134-44.

[28] C. Lopez-Garcia, A.M. Klein, B.D. Simons, D.J. Winton, Intestinal stem cell replacement follows a pattern of neutral drift, Science 330(6005) (2010) 822-5.

[29] P. Martinelli, F. Madriles, M. Canamero, E.C. Pau, N.D. Pozo, C. Guerra, F.X. Real, The acinar regulator Gata6 suppresses KrasG12V-driven pancreatic tumorigenesis in mice, Gut 65(3) (2016) 476-86.

[30] C. Bonal, F. Thorel, A. Ait-Lounis, W. Reith, A. Trumpp, P.L. Herrera, Pancreatic inactivation of c-Myc decreases acinar mass and transdifferentiates acinar cells into adipocytes in mice, Gastroenterology 136(1) (2009) 309-319 e9.

[31] C.L. Chaffer, I. Brueckmann, C. Scheel, A.J. Kaestli, P.A. Wiggins, L.O. Rodrigues, M. Brooks, F. Reinhardt, Y. Su, K. Polyak, L.M. Arendt, C. Kuperwasser, B. Bierie, R.A. Weinberg, Normal and 
neoplastic nonstem cells can spontaneously convert to a stem-like state, Proc Natl Acad Sci U S A 108(19) (2011) 7950-5.

[32] T. Lapidot, C. Sirard, J. Vormoor, B. Murdoch, T. Hoang, J. Caceres-Cortes, M. Minden, B. Paterson, M.A. Caligiuri, J.E. Dick, A cell initiating human acute myeloid leukaemia after transplantation into SCID mice, Nature 367(6464) (1994) 645-8.

[33] M. Al-Hajj, M.S. Wicha, A. Benito-Hernandez, S. Morrison, M.F. Clarke, Prospective identification of tumorigenic breast cancer cells, Proc Natl Acad Sci USA 100(7) (2003) 3983-8.

[34] C.A. O'Brien, A. Pollett, S. Gallinger, J.E. Dick, A human colon cancer cell capable of initiating tumour growth in immunodeficient mice, Nature 445(7123) (2007) 106-10.

[35] L. Ricci-Vitiani, D.G. Lombardi, E. Pilozzi, M. Biffoni, M. Todaro, C. Peschle, R. De Maria, Identification and expansion of human colon-cancer-initiating cells, Nature 445(7123) (2007) 111-5.

[36] P. Dalerba, S.J. Dylla, I.K. Park, R. Liu, X. Wang, R.W. Cho, T. Hoey, A. Gurney, E.H. Huang, D.M. Simeone, A.A. Shelton, G. Parmiani, C. Castelli, M.F. Clarke, Phenotypic characterization of human colorectal cancer stem cells, Proc Natl Acad Sci USA 104(24) (2007) 10158-63.

[37] S.K. Singh, C. Hawkins, I.D. Clarke, J.A. Squire, J. Bayani, T. Hide, R.M. Henkelman, M.D. Cusimano, P.B. Dirks, Identification of human brain tumour initiating cells, Nature 432(7015) (2004) 396-401.

[38] A.T. Collins, P.A. Berry, C. Hyde, M.J. Stower, N.J. Maitland, Prospective identification of tumorigenic prostate cancer stem cells, Cancer Res 65(23) (2005) 10946-51.

[39] I. Miranda-Lorenzo, J. Dorado, E. Lonardo, S. Alcala, A.G. Serrano, J. Clausell-Tormos, M. Cioffi, D. Megias, S. Zagorac, A. Balic, M. Hidalgo, M. Erkan, J. Kleeff, A. Scarpa, B. Sainz, Jr., C. Heeschen, Intracellular autofluorescence: a biomarker for epithelial cancer stem cells, Nat Methods 11(11) (2014) 1161-9.

[40] S. Zhang, C. Balch, M.W. Chan, H.C. Lai, D. Matei, J.M. Schilder, P.S. Yan, T.H. Huang, K.P. Nephew, Identification and characterization of ovarian cancer-initiating cells from primary human tumors, Cancer Res 68(11) (2008) 4311-20.

[41] A. Eramo, F. Lotti, G. Sette, E. Pilozzi, M. Biffoni, A. Di Virgilio, C. Conticello, L. Ruco, C. Peschle, R. De Maria, Identification and expansion of the tumorigenic lung cancer stem cell population, Cell Death Differ 15(3) (2008) 504-14.

[42] P.N. Kelly, A. Dakic, J.M. Adams, S.L. Nutt, A. Strasser, Tumor growth need not be driven by rare cancer stem cells, Science 317(5836) (2007) 337.

[43] E. Quintana, M. Shackleton, M.S. Sabel, D.R. Fullen, T.M. Johnson, S.J. Morrison, Efficient tumour formation by single human melanoma cells, Nature 456(7222) (2008) 593-8.

[44] G. Driessens, B. Beck, A. Caauwe, B.D. Simons, C. Blanpain, Defining the mode of tumour growth by clonal analysis, Nature 488(7412) (2012) 527-30.

[45] A.G. Schepers, H.J. Snippert, D.E. Stange, M. van den Born, J.H. van Es, M. van de Wetering, $\mathrm{H}$. Clevers, Lineage tracing reveals Lgr5+ stem cell activity in mouse intestinal adenomas, Science 337(6095) (2012) 730-5.

[46] R. Maddipati, B.Z. Stanger, Pancreatic Cancer Metastases Harbor Evidence of Polyclonality, Cancer Discov 5(10) (2015) 1086-97.

[47] S.M. Dieter, C.R. Ball, C.M. Hoffmann, A. Nowrouzi, F. Herbst, O. Zavidij, U. Abel, A. Arens, W. Weichert, K. Brand, M. Koch, J. Weitz, M. Schmidt, C. von Kalle, H. Glimm, Distinct types of tumor-initiating cells form human colon cancer tumors and metastases, Cell Stem Cell 9(4) (2011) 357-65.

[48] C. Cortina, G. Turon, D. Stork, X. Hernando-Momblona, M. Sevillano, M. Aguilera, S. Tosi, A. Merlos-Suarez, C. Stephan-Otto Attolini, E. Sancho, E. Batlle, A genome editing approach to study cancer stem cells in human tumors, EMBO Mol Med 9(7) (2017) 869-879.

[49] C.R. Ball, F. Oppel, K.R. Ehrenberg, T.D. Dubash, S.M. Dieter, C.M. Hoffmann, U. Abel, F. Herbst, M. Koch, J. Werner, F. Bergmann, N. Ishaque, M. Schmidt, C. von Kalle, C. Scholl, S. Frohling, B. Brors, W. Weichert, J. Weitz, H. Glimm, Succession of transiently active tumor- 
initiating cell clones in human pancreatic cancer xenografts, EMBO Mol Med 9(7) (2017) 918932.

[50] U.R. Rapp, F. Ceteci, R. Schreck, Oncogene-induced plasticity and cancer stem cells, Cell Cycle 7(1) (2008) 45-51.

[51] M. Rahman, L. Deleyrolle, V. Vedam-Mai, H. Azari, M. Abd-El-Barr, B.A. Reynolds, The cancer stem cell hypothesis: failures and pitfalls, Neurosurgery 68(2) (2011) 531-45; discussion 545.

[52] X. Zheng, G. Shen, X. Yang, W. Liu, Most C6 cells are cancer stem cells: evidence from clonal and population analyses, Cancer Res 67(8) (2007) 3691-7.

[53] P.B. Gupta, C.M. Fillmore, G. Jiang, S.D. Shapira, K. Tao, C. Kuperwasser, E.S. Lander, Stochastic state transitions give rise to phenotypic equilibrium in populations of cancer cells, Cell 146(4) (2011) 633-44.

[54] N. McCarthy, That's the theory, Nat Rev Cancer 11(10) (2011) 691.

[55] F. de Sousa e Melo, A.V. Kurtova, J.M. Harnoss, N. Kljavin, J.D. Hoeck, J. Hung, J.E. Anderson, E.E. Storm, Z. Modrusan, H. Koeppen, G.J. Dijkgraaf, R. Piskol, F.J. de Sauvage, A distinct role for Lgr5(+) stem cells in primary and metastatic colon cancer, Nature 543(7647) (2017) 676-680.

[56] M. Shimokawa, Y. Ohta, S. Nishikori, M. Matano, A. Takano, M. Fujii, S. Date, S. Sugimoto, T. Kanai, T. Sato, Visualization and targeting of LGR5(+) human colon cancer stem cells, Nature 545(7653) (2017) 187-192.

[57] J. Chen, Y. Li, T.S. Yu, R.M. McKay, D.K. Burns, S.G. Kernie, L.F. Parada, A restricted cell population propagates glioblastoma growth after chemotherapy, Nature 488(7412) (2012) 5226.

[58] D. Hanahan, L.M. Coussens, Accessories to the crime: functions of cells recruited to the tumor microenvironment, Cancer Cell 21(3) (2012) 309-22.

[59] V. Plaks, N. Kong, Z. Werb, The cancer stem cell niche: how essential is the niche in regulating stemness of tumor cells?, Cell Stem Cell 16(3) (2015) 225-38.

[60] S. Hamada, A. Masamune, T. Shimosegawa, Alteration of pancreatic cancer cell functions by tumor-stromal cell interaction, Front Physiol 4 (2013) 318.

[61] M.V. Apte, Z. Xu, S. Pothula, D. Goldstein, R.C. Pirola, J.S. Wilson, Pancreatic cancer: The microenvironment needs attention too!, Pancreatology 15(4 Suppl) (2015) S32-8.

[62] A.B. Seymour, R.H. Hruban, M. Redston, C. Caldas, S.M. Powell, K.W. Kinzler, C.J. Yeo, S.E. Kern, Allelotype of pancreatic adenocarcinoma, Cancer Res 54(10) (1994) 2761-4.

[63] M. Erkan, C. Reiser-Erkan, C.W. Michalski, S. Deucker, D. Sauliunaite, S. Streit, I. Esposito, H. Friess, J. Kleeff, Cancer-stellate cell interactions perpetuate the hypoxia-fibrosis cycle in pancreatic ductal adenocarcinoma, Neoplasia 11(5) (2009) 497-508.

[64] M. Erkan, Understanding the stroma of pancreatic cancer: co-evolution of the microenvironment with epithelial carcinogenesis, J Pathol 231(1) (2013) 4-7.

[65] M. Erkan, The role of pancreatic stellate cells in pancreatic cancer, Pancreatology 13(2) (2013) 106-9.

[66] M.G. Bachem, M. Schunemann, M. Ramadani, M. Siech, H. Beger, A. Buck, S. Zhou, A. Schmid-Kotsas, G. Adler, Pancreatic carcinoma cells induce fibrosis by stimulating proliferation and matrix synthesis of stellate cells, Gastroenterology 128(4) (2005) 907-21.

[67] E. Lonardo, J. Frias-Aldeguer, P.C. Hermann, C. Heeschen, Pancreatic stellate cells form a niche for cancer stem cells and promote their self-renewal and invasiveness, Cell Cycle 11(7) (2012) 1282-90.

[68] B. Farrow, Y. Sugiyama, A. Chen, E. Uffort, W. Nealon, B. Mark Evers, Inflammatory mechanisms contributing to pancreatic cancer development, Ann Surg 239(6) (2004) 763-9; discussion 769-71.

[69] G.C. Chu, A.C. Kimmelman, A.F. Hezel, R.A. DePinho, Stromal biology of pancreatic cancer, J Cell Biochem 101(4) (2007) 887-907.

[70] C.E. Clark, S.R. Hingorani, R. Mick, C. Combs, D.A. Tuveson, R.H. Vonderheide, Dynamics of the immune reaction to pancreatic cancer from inception to invasion, Cancer Res 67(19) (2007) 9518-27. 
[71] T. Sangai, G. Ishii, K. Kodama, S. Miyamoto, Y. Aoyagi, T. Ito, J. Magae, H. Sasaki, T. Nagashima, M. Miyazaki, A. Ochiai, Effect of differences in cancer cells and tumor growth sites on recruiting bone marrow-derived endothelial cells and myofibroblasts in cancer-induced stroma, Int J Cancer 115(6) (2005) 885-92.

[72] R. Kalluri, M. Zeisberg, Fibroblasts in cancer, Nat Rev Cancer 6(5) (2006) 392-401.

[73] M.V. Apte, J.S. Wilson, A. Lugea, S.J. Pandol, A starring role for stellate cells in the pancreatic cancer microenvironment, Gastroenterology 144(6) (2013) 1210-9.

[74] S. Hamada, A. Masamune, T. Takikawa, N. Suzuki, K. Kikuta, M. Hirota, H. Hamada, M. Kobune, K. Satoh, T. Shimosegawa, Pancreatic stellate cells enhance stem cell-like phenotypes in pancreatic cancer cells, Biochem Biophys Res Commun 421(2) (2012) 349-54.

[75] Z. Xu, A. Vonlaufen, P.A. Phillips, E. Fiala-Beer, X. Zhang, L. Yang, A.V. Biankin, D. Goldstein, R.C. Pirola, J.S. Wilson, M.V. Apte, Role of pancreatic stellate cells in pancreatic cancer metastasis, Am J Pathol 177(5) (2010) 2585-96.

[76] D. Tang, D. Wang, Z. Yuan, X. Xue, Y. Zhang, Y. An, J. Chen, M. Tu, Z. Lu, J. Wei, K. Jiang, Y. Miao, Persistent activation of pancreatic stellate cells creates a microenvironment favorable for the malignant behavior of pancreatic ductal adenocarcinoma, Int J Cancer 132(5) (2013) 9931003.

[77] A. Kanno, K. Satoh, A. Masamune, M. Hirota, K. Kimura, J. Umino, S. Hamada, A. Satoh, S. Egawa, F. Motoi, M. Unno, T. Shimosegawa, Periostin, secreted from stromal cells, has biphasic effect on cell migration and correlates with the epithelial to mesenchymal transition of human pancreatic cancer cells, Int J Cancer 122(12) (2008) 2707-18.

[78] I. Paron, S. Berchtold, J. Voros, M. Shamarla, M. Erkan, H. Hofler, I. Esposito, Tenascin-C enhances pancreatic cancer cell growth and motility and affects cell adhesion through activation of the integrin pathway, PLoS One 6(6) (2011) e21684.

[79] Y. Xu, H. Li, C. Huang, T. Zhao, H. Zhang, C. Zheng, H. Ren, J. Hao, Wnt2 protein plays a role in the progression of pancreatic cancer promoted by pancreatic stellate cells, Med Oncol 32(4) (2015) 97.

[80] Y. Liu, F. Li, F. Gao, L. Xing, P. Qin, X. Liang, J. Zhang, X. Qiao, L. Lin, Q. Zhao, L. Du, Role of microenvironmental periostin in pancreatic cancer progression, Oncotarget 8(52) (2017) 8955289565.

[81] Y.S. Wu, I. Chung, W.F. Wong, A. Masamune, M.S. Sim, C.Y. Looi, Paracrine IL-6 signaling mediates the effects of pancreatic stellate cells on epithelial-mesenchymal transition via Stat3/Nrf2 pathway in pancreatic cancer cells, Biochim Biophys Acta 1861(2) (2017) 296-306.

[82] C.A. Orozco, N. Martinez-Bosch, P.E. Guerrero, J. Vinaixa, T. Dalotto-Moreno, M. Iglesias, M. Moreno, M. Djurec, F. Poirier, H.J. Gabius, M.E. Fernandez-Zapico, R.F. Hwang, C. Guerra, G.A. Rabinovich, P. Navarro, Targeting galectin-1 inhibits pancreatic cancer progression by modulating tumor-stroma crosstalk, Proc Natl Acad Sci U S A 115(16) (2018) E3769-E3778.

[83] W. Shen, G.Q. Tao, Y. Zhang, B. Cai, J. Sun, Z.Q. Tian, TGF-beta in pancreatic cancer initiation and progression: two sides of the same coin, Cell Biosci 7 (2017) 39.

[84] E. Lonardo, P.C. Hermann, M.T. Mueller, S. Huber, A. Balic, I. Miranda-Lorenzo, S. Zagorac, S. Alcala, I. Rodriguez-Arabaolaza, J.C. Ramirez, R. Torres-Ruiz, E. Garcia, M. Hidalgo, D.A. Cebrian, R. Heuchel, M. Lohr, F. Berger, P. Bartenstein, A. Aicher, C. Heeschen, Nodal/Activin signaling drives self-renewal and tumorigenicity of pancreatic cancer stem cells and provides a target for combined drug therapy, Cell Stem Cell 9(5) (2011) 433-46.

[85] M. Cioffi, S.M. Trabulo, Y. Sanchez-Ripoll, I. Miranda-Lorenzo, E. Lonardo, J. Dorado, C. Reis Vieira, J.C. Ramirez, M. Hidalgo, A. Aicher, S. Hahn, B. Sainz, Jr., C. Heeschen, The miR-17-92 cluster counteracts quiescence and chemoresistance in a distinct subpopulation of pancreatic cancer stem cells, Gut 54(12) (2015) 1936-48.

[86] S. Zagorac, S. Alcala, G. Fernandez Bayon, T. Bou Kheir, M. Schoenhals, A. Gonzalez-Neira, M. Fernandez Fraga, A. Aicher, C. Heeschen, B. Sainz, Jr., DNMT1 Inhibition Reprograms Pancreatic Cancer Stem Cells via Upregulation of the miR-17-92 Cluster, Cancer Res 76(15) (2016) 4546-58. 
[87] L.A. Geary, K.A. Nash, H. Adisetiyo, M. Liang, C.P. Liao, J.H. Jeong, E. Zandi, P. Roy-Burman, CAF-secreted annexin A1 induces prostate cancer cells to gain stem cell-like features, Mol Cancer Res 12(4) (2014) 607-21.

[88] E.Y. Lau, J. Lo, B.Y. Cheng, M.K. Ma, J.M. Lee, J.K. Ng, S. Chai, C.H. Lin, S.Y. Tsang, S. Ma, I.O. $\mathrm{Ng}$, T.K. Lee, Cancer-Associated Fibroblasts Regulate Tumor-Initiating Cell Plasticity in Hepatocellular Carcinoma through c-Met/FRA1/HEY1 Signaling, Cell Rep 15(6) (2016) 1175-89.

[89] J. Baulida, A. Garcia de Herreros, Snail1-driven plasticity of epithelial and mesenchymal cells sustains cancer malignancy, Biochim Biophys Acta 1856(1) (2015) 55-61.

[90] P. Szabo, M. Kolar, B. Dvorankova, L. Lacina, J. Stork, C. Vlcek, H. Strnad, M. Tvrdek, K. Smetana, Jr., Mouse 3T3 fibroblasts under the influence of fibroblasts isolated from stroma of human basal cell carcinoma acquire properties of multipotent stem cells, Biol Cell 103(5) (2011) 233-48.

[91] K. Xu, X. Tian, S.Y. Oh, M. Movassaghi, S.P. Naber, C. Kuperwasser, R.J. Buchsbaum, The fibroblast Tiam1-osteopontin pathway modulates breast cancer invasion and metastasis, Breast Cancer Res 18(1) (2016) 14.

[92] A. Mantovani, S. Sozzani, M. Locati, P. Allavena, A. Sica, Macrophage polarization: tumorassociated macrophages as a paradigm for polarized M2 mononuclear phagocytes, Trends Immunol 23(11) (2002) 549-55.

[93] A. Sica, T. Schioppa, A. Mantovani, P. Allavena, Tumour-associated macrophages are a distinct $\mathrm{M} 2$ polarised population promoting tumour progression: potential targets of anti-cancer therapy, Eur J Cancer 42(6) (2006) 717-27.

[94] F. Balkwill, A. Mantovani, Inflammation and cancer: back to Virchow?, Lancet 357(9255) (2001) 539-45.

[95] H. Kurahara, H. Shinchi, Y. Mataki, K. Maemura, H. Noma, F. Kubo, M. Sakoda, S. Ueno, S. Natsugoe, S. Takao, Significance of M2-polarized tumor-associated macrophage in pancreatic cancer, J Surg Res 167(2) (2011) e211-9.

[96] P. Allavena, A. Sica, G. Solinas, C. Porta, A. Mantovani, The inflammatory micro-environment in tumor progression: the role of tumor-associated macrophages, Crit Rev Oncol Hematol 66(1) (2008) 1-9.

[97] B. Sainz, Jr., E. Carron, M. Vallespinos, H.L. Machado, Cancer Stem Cells and Macrophages: Implications in Tumor Biology and Therapeutic Strategies, Mediators of inflammation 2016 (2016) 9012369.

[98] M.A. Shields, S. Dangi-Garimella, S.B. Krantz, D.J. Bentrem, H.G. Munshi, Pancreatic cancer cells respond to type I collagen by inducing snail expression to promote membrane type 1 matrix metalloproteinase-dependent collagen invasion, J Biol Chem 286(12) (2011) 10495-504.

[99] C.S. Wegner, J.V. Gaustad, L.M. Andersen, T.G. Simonsen, E.K. Rofstad, Diffusion-weighted and dynamic contrast-enhanced MRI of pancreatic adenocarcinoma xenografts: associations with tumor differentiation and collagen content, Journal of translational medicine 14(1) (2016) 161.

[100] M. Erkan, C.W. Michalski, S. Rieder, C. Reiser-Erkan, I. Abiatari, A. Kolb, N.A. Giese, I. Esposito, H. Friess, J. Kleeff, The activated stroma index is a novel and independent prognostic marker in pancreatic ductal adenocarcinoma, Clin Gastroenterol Hepatol 6(10) (2008) 1155-61. [101] G. Biondani, K. Zeeberg, M.R. Greco, S. Cannone, I. Dando, E. Dalla Pozza, M. Mastrodonato, S. Forciniti, V. Casavola, M. Palmieri, S.J. Reshkin, R.A. Cardone, Extracellular matrix composition modulates PDAC parenchymal and stem cell plasticity and behavior through the secretome, FEBS J (2018).

[102] S. Berchtold, B. Grunwald, A. Kruger, A. Reithmeier, T. Hahl, T. Cheng, A. Feuchtinger, D. Born, M. Erkan, J. Kleeff, I. Esposito, Collagen type $V$ promotes the malignant phenotype of pancreatic ductal adenocarcinoma, Cancer Lett 356(2 Pt B) (2015) 721-32.

[103] J.M. Smigiel, N. Parameswaran, M.W. Jackson, Targeting Pancreatic Cancer Cell Plasticity: The Latest in Therapeutics, Cancers (Basel) 10(1) (2018). 
[104] P.C. Hermann, S.M. Trabulo, B. Sainz, Jr., A. Balic, E. Garcia, S.A. Hahn, M. Vandana, S.K. Sahoo, P. Tunici, A. Bakker, M. Hidalgo, C. Heeschen, Multimodal Treatment Eliminates Cancer Stem Cells and Leads to Long-Term Survival in Primary Human Pancreatic Cancer Tissue Xenografts, PLoS One 8(6) (2013) e66371.

[105] E. Lonardo, P.C. Hermann, M.-T. Mueller, S. Huber, A. Balic, I. Miranda-Lorenzo, S. Zagorac, S. Alcala, I. Rodriguez-Arabaolaza, J.C. Ramirez, R. Torres-Ruíz, E. Garcia, M. Hidaldo, D.Á. Cebrián, R. Heuchel, M. Löhr, F. Berger, P. Bartenstein, A. Aicher, C. Heeschen, Nodal/Activin signaling drives self-renewal and tumorigenicity of pancreatic cancer stem cells and provides a target for combined drug therapy., Cell Stem Cell (2011).

[106] M.T. Mueller, P.C. Hermann, J. Witthauer, B. Rubio-Viqueira, S.F. Leicht, S. Huber, J.W. Ellwart, M. Mustafa, P. Bartenstein, J.G. D'Haese, M.H. Schoenberg, F. Berger, K.W. Jauch, M. Hidalgo, C. Heeschen, Combined targeted treatment to eliminate tumorigenic cancer stem cells in human pancreatic cancer, Gastroenterology 137(3) (2009) 1102-13.

[107] A. Neesse, P. Michl, K.K. Frese, C. Feig, N. Cook, M.A. Jacobetz, M.P. Lolkema, M. Buchholz, K.P. Olive, T.M. Gress, D.A. Tuveson, Stromal biology and therapy in pancreatic cancer, Gut, 2010, pp. 1-8.

[108] A.H. Ko, N. LoConte, M.A. Tempero, E.J. Walker, R. Kate Kelley, S. Lewis, W.C. Chang, E. Kantoff, M.W. Vannier, D.V. Catenacci, A.P. Venook, H.L. Kindler, A Phase I Study of FOLFIRINOX Plus IPI-926, a Hedgehog Pathway Inhibitor, for Advanced Pancreatic Adenocarcinoma, Pancreas 45(3) (2016) 370-5.

[109] M. Lauth, A. Bergstrom, T. Shimokawa, U. Tostar, Q. Jin, V. Fendrich, C. Guerra, M. Barbacid, R. Toftgard, DYRK1B-dependent autocrine-to-paracrine shift of Hedgehog signaling by mutant RAS, Nat Struct Mol Biol 17(6) (2010) 718-25.

[110] M. Kahn, Can we safely target the WNT pathway?, Nat Rev Drug Discov 13(7) (2014) 51332.

[111] N. Takebe, P.J. Harris, R.Q. Warren, S.P. Ivy, Targeting cancer stem cells by inhibiting Wnt, Notch, and Hedgehog pathways, Nat Rev Clin Oncol 8(2) (2011) 97-106.

[112] E.R. Andersson, U. Lendahl, Therapeutic modulation of Notch signalling--are we there yet?, Nat Rev Drug Discov 13(5) (2014) 357-78.

[113] P. Sancho, E. Burgos-Ramos, A. Tavera, T. Bou Kheir, P. Jagust, M. Schoenhals, D. Barneda, K. Sellers, R. Campos-Olivas, O. Grana, C.R. Viera, M. Yuneva, B. Sainz, Jr., C. Heeschen, MYC/PGC-1alpha Balance Determines the Metabolic Phenotype and Plasticity of Pancreatic Cancer Stem Cells, Cell Metab 22(4) (2015) 590-605.

[114] E. Lonardo, M. Cioffi, P. Sancho, Y. Sanchez-Ripoll, S.M. Trabulo, J. Dorado, A. Balic, M. Hidalgo, C. Heeschen, Metformin targets the metabolic achilles heel of human pancreatic cancer stem cells, PLoS One 8(10) (2013) e76518.

[115] B. Sainz, Jr., S. Alcala, E. Garcia, Y. Sanchez-Ripoll, M.M. Azevedo, M. Cioffi, M. Tatari, I. Miranda-Lorenzo, M. Hidalgo, G. Gomez-Lopez, M. Canamero, M. Erkan, J. Kleeff, S. Garcia-Silva, P. Sancho, P.C. Hermann, C. Heeschen, Microenvironmental hCAP-18/LL-37 promotes pancreatic ductal adenocarcinoma by activating its cancer stem cell compartment, Gut 64(12) (2015) 1921-35.

[116] B. Sainz, Jr., B. Martin, M. Tatari, C. Heeschen, S. Guerra, ISG15 is a critical microenvironmental factor for pancreatic cancer stem cells, Cancer Res 74(24) (2014) 7309-20.

[117] C.D. Swaim, A.F. Scott, L.A. Canadeo, J.M. Huibregtse, Extracellular ISG15 Signals Cytokine Secretion through the LFA-1 Integrin Receptor, Mol Cell 68(3) (2017) 581-590 e5.

[118] C.L. Chaffer, R.A. Weinberg, How does multistep tumorigenesis really proceed?, Cancer Discov 5(1) (2015) 22-4. 
Figure 1: The Cancer Stem Cell (CSC) model. CSCs share phenotypes and characteristics of normal stem cells, such as unlimited self-renewal, which assures the survival of the CSC pool and supports the hierarchical model of tumor cell heterogeneity. CSCs also possess the capacity to divide symmetrically or asymmetrically, generating more CSCs or the multiple cell lineages present within the tumor bulk, including progenitor/transient cells and more differentiated tumor cells. The degrees of pluripotency, plasticity and chemoresistance are believed to correlate with the level of cellular differentiation and degree of heterogeneity. The less differentiated and heterogenous cells possesses more stem-like characteristics and are more plastic; however, progenitor/transient cells (and differentiated tumor cell to some degree) are also plastic under certain circumstances.

Figure 2: The Tumor Microenvironment. PDAC is characterized by a high desmoplastic reaction, resulting in a dense ECM-rich and hypoxic stroma. Apart from the tumor cells and CSCs, the PDAC tumor bulk, or microenvironment, is composed of pancreatic stellate cells (PaSC), [often referred to as cancer-associated fibroblasts (CAFs)], immune cells including tumor-associated macrophages (TAMs) and T-cells, endothelial cells, and neuronal cells/nerve fibers. While individually all of these cellular components have their specific function(s) within the TME, they communicate with each other and with the CSC via secreted factors, creating a dynamic and complex TME. Adapted from [24].

Figure 3: The CSC niche. CSCs are believed to reside in a niche within the TME. The niche is a smaller anatomically distinct and more specialized TME sub-compartment, which regulates CSC fate through cell-to-cell contacts or via cues from secreted niche milieu factors. Different CSC niches can exist and dominate at any given time during the evolution of the tumor. If the CSC is lost, there is competition for other cells to reenter the niche to replace the CSC. This process, known as neutral competition in normal stem cell niches, is where stem cells progenies respond to extrinsic signaling factors and compete to occupy the niche. The same is believed to occur in tumors. Progenitor cells, transient cells and even "committed" differentiated tumor cells can undergo phenotypic transitions and transconvert into a CSC, a process known as cellular plasticity. In addition, it is likely that other CSCs (perhaps quiescent CSCS), can reoccupy the niche; however, the degree of plasticity and capacity to undergo phenotypic transitions will likely determine what cell type reenters the niche. Adapted from [24]. 
Figure 1: The Cancer Stem Cell (CSC) model.

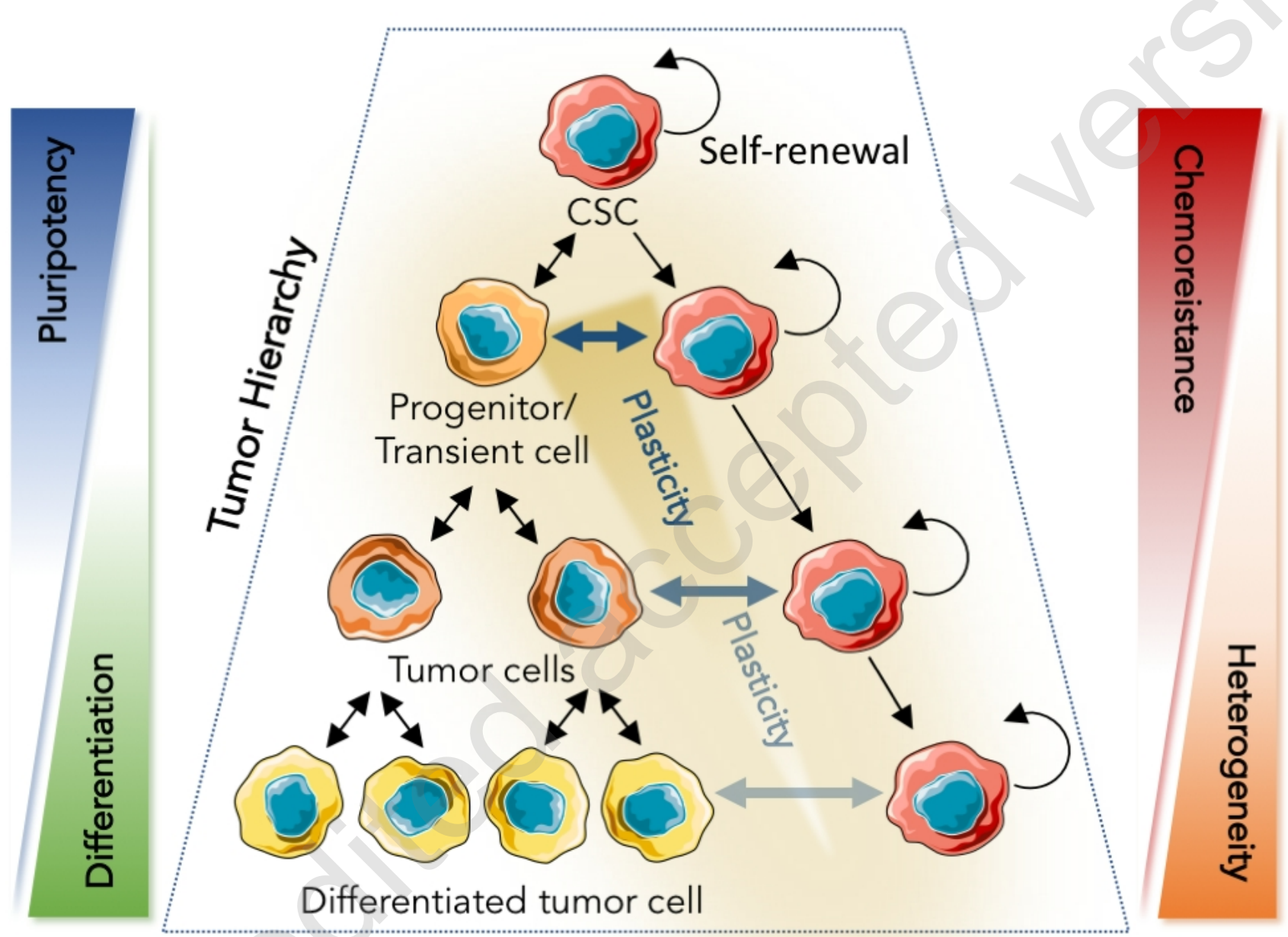



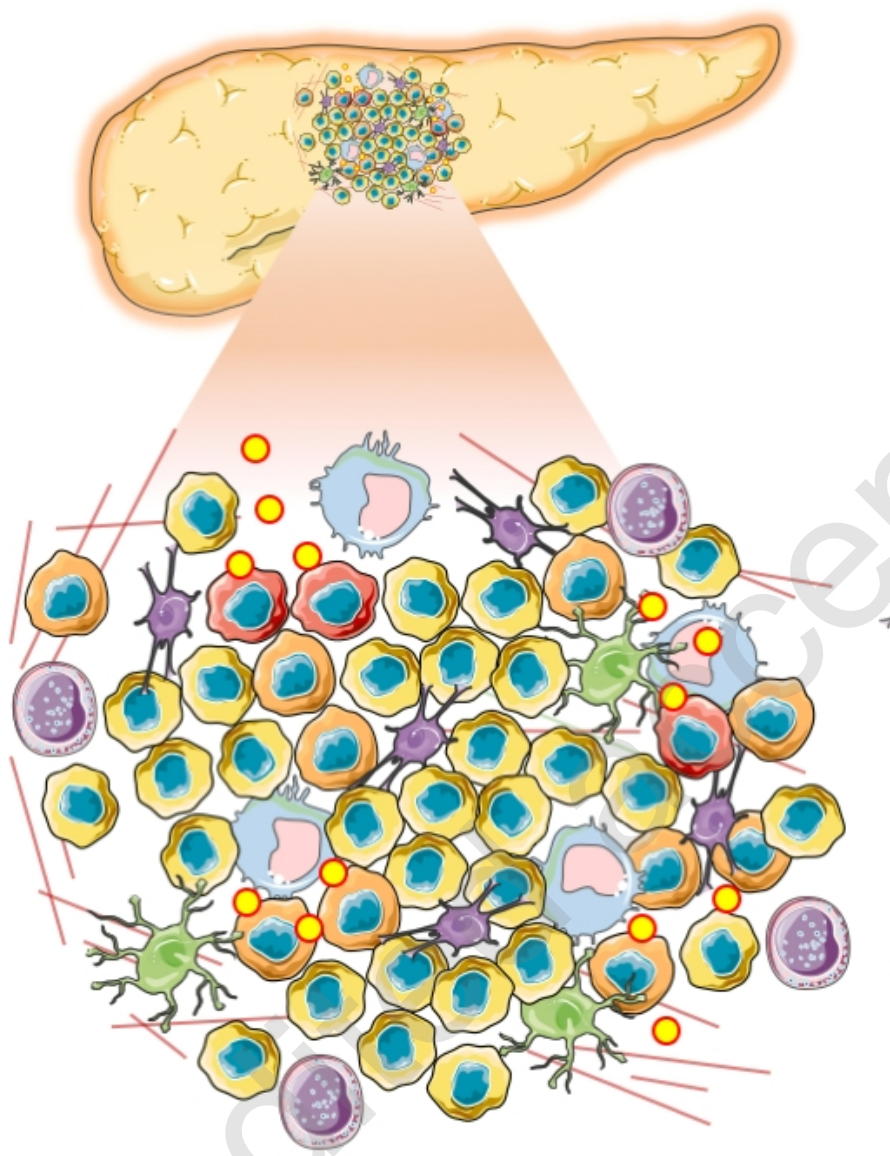

(2) Tumor cell

(3) Cancer Stem Cell (CSC)

(C) Macrophage (TAM)

Fibroblast (CAF)

) Stellate cell (PaSC)

(3) T-cell

Secreted factor

$\checkmark$ ECM fiber 


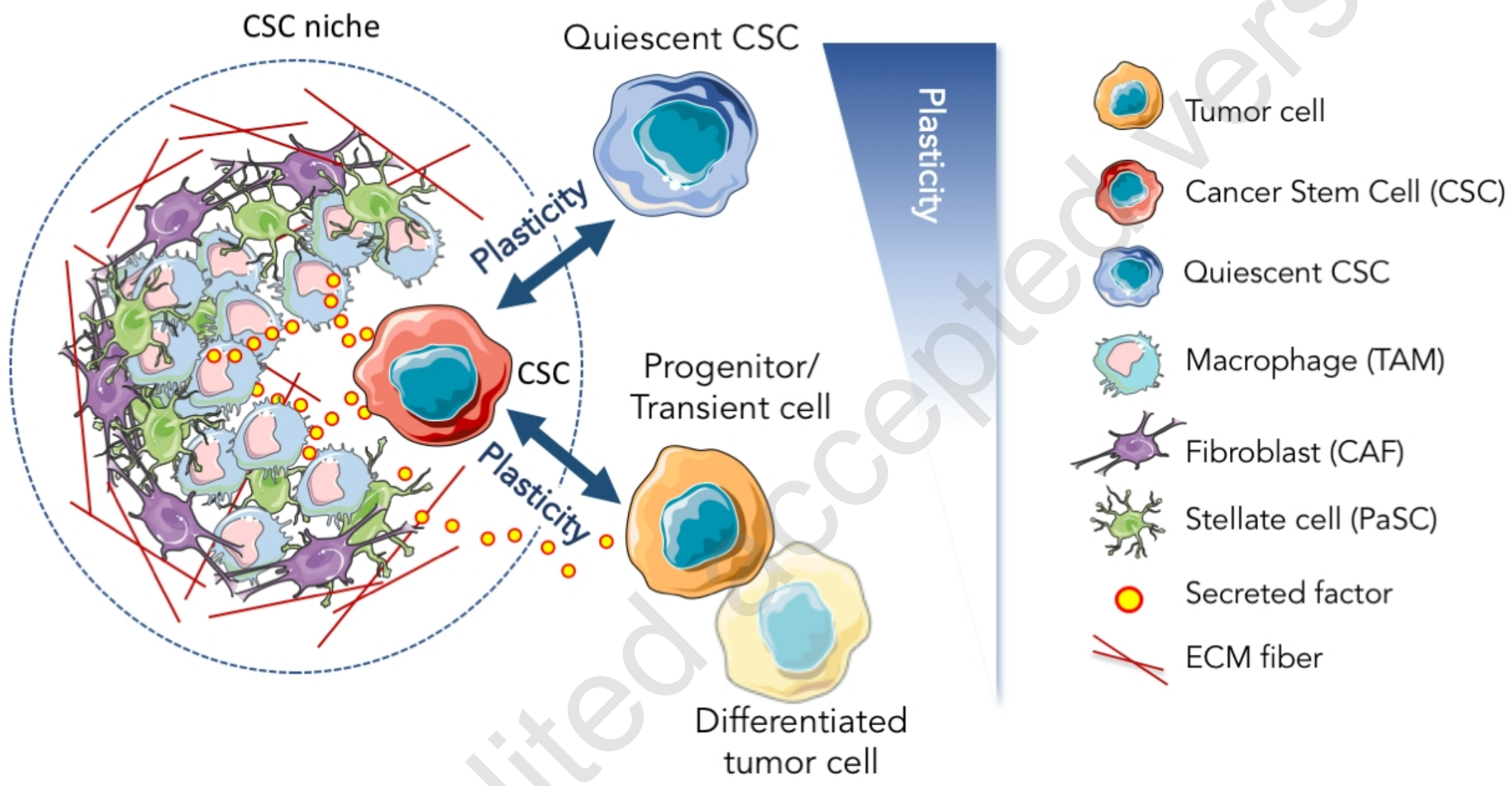

